\title{
HEALTH LITERACY OF THE POPULATION IN BULGARIA - POLICIES, PROGRAMS AND GUIDELINES FOR IMPROVEMENT
}

\author{
S. Garov*, T. Popov \\ Faculty of Public Health, Medical University - Sofia, Bulgaria
}

\begin{abstract}
The lasting unfavourable tendency of unhealthy lifestyles for a large part of the population in Bulgaria due to poor health culture and poor health literacy has emerged as an increasingly relevant and important topic for the need to increase health literacy of the Bulgarians.

According to the present perceptions, the role of health professionals in health education, along with those in the education sector, is increasingly growing. The new models of the medical professional-topatient relationship enable healthcare workers to effectively increase people's awareness and skills by promoting healthy lifestyle and highlighting the health promotion and disease prevention.
\end{abstract}

Key words: health literacy; health culture; health education, medical professional.

\section{INTRODUCTION}

The governance programme of the Government of the Republic of Bulgaria for the period 2017-2021 underlines that the country will focus its efforts on improving the health of the population. A direct relation to the topic of the this work is the formulated Priority 33, Measure 393 from this programme, which states: "Improving and increasing the awareness of the population of basic risk factors (smoking, alcohol abuse, unhealthy nutrition, low physical activity), which have a relation to the chronic non-infectious diseases as well as of the new risk factors, new medical technologies and methods for improving health, with the aim of overcoming the low health literacy and enhancing the well-being of the citizens." (1)

\section{PURPOSE}

The purpose of this article is to analyze the health literacy policies and programs, which were used in Bulgaria.

\section{METHODS}

A documentary research method was used in collecting relevant information in this study on Health Literacy. The documentary method is described as the technique used to categorize,

\footnotetext{
*Correspondence to: Svetoslav Garov, Department "Medical pedagogy", Faculty of Public Health, Medical University - Sofia, Sofia 1527, No.8 Byalo More Str., email:sv.garov@gmail.com
}

investigate, and interpret written documents whether in the private or public domain.

\section{RESULTS}

\section{Programmes for health literacy in} Bulgaria

More than 10 years ago Bulgaria began a training programme called "Health mediator". It is carried out under the National PHARE programme 2003, project "Education and medical integration of the vulnerable minority groups with special focus on the Roma. Component 03: Healthcare". The programme aims to improve access of minority groups to the healthcare system, as well as the capabilities of the system to solve the healthcare problems of these communities. The realization of this training programme for acquiring the professional qualification "health mediator" helps the process of mediation between vulnerable groups and the responsible health institutions and this way aims to ensure equal access to healthcare services for all citizens of Bulgaria. (2)

Individuals who have completed the programme gain the professional qualification of "health mediator" and can work in government administrations, as well as in individual and group medical practices, regional health inspectorates (RHI) or nongovernment organizations. Individuals who pass this programme gain professional competences to help patients formulate their 
health needs, when receiving healthcare services and when following doctors' prescriptions and recommendations.

Individuals who have completed the programme have the following skills and knowledge:

- Working with people with health problems who may have issues when searching and receiving health services.

- Assist in the process of access to services in the sphere of healthcare;

- Help the liaisons of their client with the Health Insurance Fund;

- Help in communicating with the Social Assistance Department, The Child Protection Agency and the Commission for Protection against Discrimination;

- Organize and carry out events to provide knowledge in the field of healthcare, as well as participate in programmes for a healthy lifestyle and prophylaxis of the population.

In the period March - April 2018 the annual training of the future health mediators took place at the Faculty of Public Health of the Medical University of Sofia, organized in cooperation with the Association of the National network of health mediators. Until 2018 the programme has helped train 230 people as health mediators, who have come from 27 regions of the country.

In the framework of several programmes of the Ministry of Health and the National Centre for Public Health, along with the UN Fund for the population and UNICEF, and consistent with Component 7 "Lowering the risky sexual behaviour among adolescent and young people in and outside of schools", the "Prevention and Control of HIV/AIDS" programme, financed by the Global Anti AIDS, Tuberculosis and Malaria Fund, implemented in Bulgaria by the Ministry of Health, and as a result of the implementation of the National plan for protecting the rights of children (2006-2009) in the period 200-2014 a number of steps were taken to ensure access of Bulgarian students to systematic health education.

The results of the HLS-EU - The European Health Literacy Survey carried out in cooperation with the Medical University of Sofia have shown that Bulgarians generally have the lowest level of health literacy as $26,9 \%$ have low and $35.2 \%$ - problematic health literacy. This means that over half of the population $(62,1 \%)$ have low health culture and by this indicator, the country ranks last among the 8 European countries in the survey. The data also show that every tenth Bulgarian
GAROV S., et al. takes an improper dose of the prescribed drug, because he/she misunderstood the information he was given during consultation or during the check up with a medical specialist. This has serious consequences for public health, as well as economic influence on health services. (3)

People over 55, those with low social status or people without (or too low) educational degree, have a hard time finding and understanding health information. Despite the fact that $81 \%$ of the respondents claim they understand what the doctor tells them, it turns out that every third person does not know what medical specialist he must turn to in an emergency. The information for prophylaxis of different diseases is random and even less understandable for them. Pensioners, unemployed, socially disadvantaged individuals, people with chronic conditions consider it most difficult to find and use health information. These are the main target groups with regard to measures for building and improving health literacy.

A worrying trend is also the low health culture among young people and adolescents. According to the national representative survey of sexual and reproductive health of young people (carried out under Project BUL1R205/BUL1R303 "Improving the sexual and reproductive health of young people in Bulgaria" at the initiative of the Ministry of Education and Science, Ministry of health and the UN Fund. (4) It lasted 5 years - from 2004 to 2009 , in a series of directions, bad tendencies regarding the health of children and young people, connected to their behaviour were established:

$>$ Risky sexual behaviour:

$\circ \quad$ start of sexual life at the age of 16-17;

$\circ$ widely spread sexual intercourses without protective means ( $40 \%$ of young people have not used a condom in their first sexual intercourse);

$\circ$ use of drugs and alcohol before sexual intercourse;

- short durations of sexual partnerships;

$\circ \quad$ maintenance of parallel sexual relationships (with more than 1 partner);

$\circ \quad$ sexual contacts for money and gifts;

high rate of early pregnancies (up to 19 years old) and number of abortions at the age of 15 to 19 (Bulgaria, along with Russia and Ukraine, ranks first in Europe as to number of births and abortions of girls in this age range); 
GAROV S., et al.

$>$ increase of the spread of sexually transmitted infections (the number of the officially registered cases for syphilis infection progressively grows over the last few years: from 409 registered cases in 2010 to 626 in 2015 , as the increased number of infected young people between 15 and 19 is extremely embarassing (based on the report by the minister of health to the National Assembly of 4.09.2017

$>$ an increase of the number of HIVinfected young people (over 50\% of the newly registered HIV-seropositive people are at the of age 15 to 29 );

$>$ widespread use of cigarettes (Bulgaria is in fourth place among the European countries with the highest spread of smoking in adolescence);

$>$ increase of the use of alcohol among school students;

$>$ increase of the abuse of psychoactive substances (26\% of the students aged 16 have tried some kind of drug at least once);

$>$ increasing number of children that have become victims of traffic accidents;

$>$ increasing the number of heart related diseases and deaths caused by them;

$>$ widespread aggression and violence in schools by kids to kids and adults.

2. Guidelines for improving the health literacy and health culture of the population Elementary, high education (high school, vocational school) and universities in Bulgaria provide various possibilities for encouraging modern built health literacy, lowering the risky to health conduct and helping kids and adolescents for their future "navigation" in the system of healthcare. The programmes for health education must start from early childhood - right as children reach school age (6-7 years old) and must constantly build up previous knowledge for achieving maximum efficiency. (5) Forming health culture must start then - in the earliest childhood age, and sustainable motivation for positive health behaviour can be achieved in the child and adolescent age at school, where they can receive and assimilate enough health information. It is also worth noting that the increase of health literacy in school students can be hindered by the lack of succession and consistency of health education programmes at various age groups. $(6,7)$. Therefore an important task of the modern school is to become a main factor in forming health culture, health education and a healthy lifestyle. $(8,9)$. Education is a process that aims to form personal qualities, attitude to the world, behaviour and norms. The educational and upbringing process go parallel, but work together and depend on each other.

All authors emphasize the tight and direct connection between education and selfeducation, which can be looked as different stages of an integral process. That is why their consistency is necessary for the realization of the school-educational process. Education and self-education are in an organic relationship, as they follow the completion and realization of a common, general aim - harmonious and wholesome development of the individual. (10, 11)

The health education is an important element of the general education and presents a specific medical-pedagogy activity that aims to increase the health culture of the population and achieving a healthy lifestyle. (12) It is a process aimed at forming health culture health knowledge, principles and behaviour, connected to improving, maintaining and restoring individual and public health.

The strategies for health education ensure providing information on specific health topics, including the benefits and threats to health and create tools for building a capacity and support for change of the behaviour of people, motivating them to live healthy.

There are three approaches to achieve health education.

1. The individual approach usually follows aims that coincide with the aims of the secondary and tertiary prophylaxis of the individuals. It includes consulting and advising the trainee or the individuals at high risk, evaluation of the risk profile of the individual, education in different conditions, using audiovisual and printed materials.

2. The group approach is directed mainly to the primary prophylaxis but it is connected to the other levels. It aims to help build and maintain the positive behaviour of a specific society/group, ensure the support of individuals in it with common (health related) problems, help the society identify and solve similar problems, organize individuals in groups to undertake change at a macro level.

3. The societal approach aims at changing the behavior of society in general. It is achieved through national health policy decisions.

The most common activities on health education are:

- Educational activities on health topics within another subject (history, biology, chemistry and etc.);

- Lectures within a more common theme/programme;

Trakia Journal of Sciences, Vol. 16, Suppl. 1, 2018 
- Courses with entirely or prevailing health theme;

- Seminars as combinations of lectures with practical exercises on various themes;

- Webinars (online seminars), etc.

\section{CONCLUSIONS}

Globally the holistic (integral) method is becoming more widespread, and it sees health as an integral model with bio-psychosocial sides, which are interconnected and affect each other. This supposes the inclusion of all sectors of social life that have relation to it. The educational and health sector have a leading role of implementing this model as the modern ideas for promotion of health are connected with the belief that health and education are inseparable.

This approach also emphasizes the necessity to take and achieve rational political decisions that influence the access to information and its use, which can have an important meaning for achieving the internationally agreed upon aims for health and development, as well as preventing global health threats such as pandemic fever, climate change, spread of infectious diseases, etc.

\section{REFERENCES}

1. Governance Programme of the government of Republic of Bulgaria for the period 2017 -2021 ;

www.dsopl2016.com/files/Government\%20 strategy\%202017-2021.docx

2. Association "National Network for Health Mediators";http://www.zdravenmediator.ne t/index.php?pagetype=text\&page_id=39
GAROV S., et al.

3. Vodenicharov, Ts. et al. Social Medicine. Textbook Sofia, Goreks Press, p. 458-461, 2013

4. Ministry of Health, EU programmes on sexual and reproductive health; http://www.mh.government.bg/bg/evropeys ki-programi/realizirani-

proekti/podobryavane-na-seksualnoto-ireproduktivno-zdrave/

5. Batoeva, D. Integrated methodology for children aged 6-7 and methodical guidance for its application. Sofia City, "Programme Step by Step" Foundation, p.6, 1999

6. Lister-Sharp, D., Chapman, S., StewartBrown, S. \& Sowden, A. Health Promoting Schools and Health Promotion in Schools: Two systematic reviews. - In: Health Technology Assessment, 3:1-207, 1999

7. St. Leger, L. \& Nutbeam, D. A Model for Mapping Linkages between Health and Education Agencies to Improve School Health. - In: Journal of School Health, 70:45-50, 2000

8. Ivanov E. Health culture of school students factor for effective promotion of health. Sofia, Goreks Press, p. 10, ISBN 978-954616-262-5, 2015

9. Mladenova, S. Health knowledge, behavior and attitude of students from V to VIII grade. - B: Sister act, b. 1, p.20-22), 2008

10. Popov, T. et al. Pedagogy Part one Theory of education. 4, ed. Gabrovo, Ex-Press, p. 118, 2018

11. Popov, T. et al. Pedagogy Part two Theory of education - didactics 3, ed. Gabrovo, ExPress, p. 89, 2015

12. Allensworth, D. Health Education: State of the Art. - In: Journal of School Health, 63:14-20, 1993 